\title{
Influence of Annealing treatment on Microstructure and Properties of Cold-drawn Al-3.0wt.\%Mg Alloy
}

\author{
Xin Zhang ${ }^{*}$, Ruiqi Ma, Zehua Wang, Zehua Zhou, Guangheng Yang, Xin Cai \\ College of Mechanics and Materials, Hohai University, Nanjing, 210098, China \\ *E-mail: zhangxin.007@163.com
}

doi: $10.20964 / 2021.01 .55$

Received: 2 October 2020 / Accepted: 11 November 2020 / Published: 30 November 2020

\begin{abstract}
The influence of annealing treatment on the microstructure, mechanical properties and corrosion behavior of cold-drawn Al-3.0 wt $\% \mathrm{Mg}$ alloy was investigated by 2D-XRD, microstructure observation, tensile test, immersion test and electrochemical measurement. The relationships between microstructure and mechanical properties of the annealed alloy wire at different temperatures were studied. The result showed that during the annealing process, recrystallized grain appeared, and there was no reaction on the second phase particles. At the same time, the intensity of deformation texture decreased, while recrystallization texture appeared. With the increase in the annealing temperature, the tensile strength of the alloy decreased linearly, while the yield strength exhibited a three-stage characteristic decrease, and the elongation to failure first increased and then decreased. In addition, there was a linear relationship between the texture intensity, grain size and the strength of the alloy wire. The annealed alloy had a better corrosion resistance than the cold-drawn alloy. However, the annealed and cold-drawn alloys had similar pitting corrosion sensibility.
\end{abstract}

Keywords: Al-3.0 wt.\%Mg alloy; cold-drawn wire; annealing temperature; mechanical properties; corrosion behaviour

\section{FULL TEXT}

(C) 2021 The Authors. Published by ESG (www.electrochemsci.org). This article is an open access article distributed under the terms and conditions of the Creative Commons Attribution license (http://creativecommons.org/licenses/by/4.0/). 